\title{
Tobacco control and health expectancy in Australia
}

\author{
C D'Arcy J Holman, Billie Corti, Robert J Donovan, Vivienne P Dawes
}

\begin{abstract}
Objective - To model the effects of successful tobacco control on health expectancy in a developed country.

Design - A comparison was made of expected numbers of years spent in different conditions of health and institutional care between "actual Australia" and a hypothetical "non-smoking Australia", using Australian life table and crosssectional health survey data.

Subjects-Adult Australians aged 18 years and older.
\end{abstract}

Main outcome measure - Health expectancies at age 18 years were expressed as the remaining years of life spent in fair to excellent health or in poor health, or or in a long-stay health establishment.

Results - In non-smoking Australia, projected length of life in fair to excellent health increased by 3.67 years (males) and 1.40 years (females). Time spent in the community in poor health fell by 0.66 years (males) and 0.30 years (females). Expected duration of bed occupancy increased in non-smoking Australia by about $0.01-0.02$ years for short-stay hospitalisation and by $0.08-0.09$ years for long-term health establishments.

Conclusion - Elimination of exposure to tobacco smoke in Australia is expected to increase life expectancy with no untoward consequences for the prevalence of ill-health.

(Tobacco Control 1993; 2 : 195-200)

Health Promotion Development and Evaluation Program, Department of Public Health and

Department of

Management, The

University of Western

Australia, Nedlands

6009, Western

Australia

C D J Holman

B Corti

R J Donovan

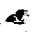

Health Services

Statistics and

Epidemiology Branch,

Health Department of

Western Australia,

189 Royal St, East

Perth 6004, Western

Australia

V P Dawes

Correspondence to: $\mathrm{Dr}$ Holman. Australia may claim to be at the forefront of the fight against tobacco. ${ }^{1,2}$ Direct advertising of cigarettes on broadcasting media was banned nationally in 1976, a print media ban was imposed in 1990, and by then other forms of tobacco advertising and promotion, including sponsorship of sport and the arts, were banned has pledged to phase out almost all tobacco advertising and promotion by 1996 . Beginning in 1979, Australian states and territories made substantial commitments, currently Aus $\$ 12$ million (US $\$ 8.4$ million) each year in total, to health promotion programmes, including mass media campaigns, client services and structural reforms, aimed at the prevention of smoking in occupying a bed in a short-stay hospital

the young and cessation in existing smokers. In addition to a federal tobacco tax of about one dollar per pack, most states impose an additional tax of about Aus $\$ 1.50$ per pack, resulting in a retail price of around Aus $\$ 4.50$ (US\$3.15) for most popular brands. Smoking was disallowed on public land transport in 1975, and on domestic airlines in 1987. Landmark legal decisions, the first occurring in 1985, have awarded compensation for the adverse consequences of passive smoking in employees and have lent strong support for the provision of a smoke-free workplace.

Health and behaviour statistics have provided evidence of the success of tobacco control activities. Per capita tobacco consumption has almost halved from 3443 grams in 1964 to 1948 grams in 1991. ${ }^{3}$ The prevalence of current smoking in Australian men fell from $45 \%$ in 1974 to $30 \%$ in $1989 .{ }^{4}$ In women, the corresponding figures were $30 \%$ and $27 \%{ }^{4}$ Lung cancer mortality is probably the most reliable long-term indicator of trends in tobaccocaused disease. In 1985-9, lung cancer mortality in Australian males fell by $6 \%$ compared with the preceding quinquennium, thus heralding the reversal of an upward trend that had continued unchecked for more than 70 years. ${ }^{5,6}$

Given the possibility that Australia may be moving gradually towards a smoke-free society, it is reasonable to pose the question: what will be the effects of this change on the health status of the Australian people? One inevitable consequence is that life expectancy will increase, but will the additional years of life be healthy and productive? Will an increase in longevity be associated with a reduced prevalence of morbidity in the living and be welcomed by those responsible for servicing their health needs?

It was estimated that in 1986 , tobacco was a in a majority of states. The federal government component cause of $21.4 \%$ of deaths in Australian males and $8.4 \%$ of deaths in females. ${ }^{7}$ These high proportions, especially for males, reflect the predominance of circulatory diseases, cancer and chronic bronchitis in the Australian mortality profile. However, while tobacco-related diseases are common causes of death, they are comparatively less common as causes of morbidity, chronic disability, and use of health services. Tobacco was a component cause in the use of just $6.6 \%$ (males) and $2.1 \%$ (females) of shortstay hospital bed days in $1986 .^{7}$ In the 1988 Australian Survey of Disability and Handicap, diseases of the musculoskeletal system and 
connective tissue, nervous system, sight loss, hearing loss, and mental disorders accounted for $64.6 \%$ of all persons with a disability. ${ }^{8}$ Few of these conditions have an established link with tobacco, and yet all are strongly agerelated. A shift in age structure towards an older population, due to a reduction in tobacco-caused mortality, would be expected to increase the crude prevalence of these conditions even if the age-specific prevalence remained constant. Therefore, a possibility exists that the end result of a successful national tobacco control programme may be a sicker society that makes greater use of health institutions.

In this paper we describe a method for estimating the projected effects of successful tobacco control on health expectancy; ie, the number of years of life spent in different conditions of health. We use the method to estimate health expectancies in a hypothetical non-smoking society. Within the limitations of the available data, we draw a comparison between the health expectancy of actual Australia in 1986-90, and a non-smoking Australia.

\section{Methods}

Health expectancies were calculated by Sullivan's method, ${ }^{9}$ with expectations of life divided among multiple conditions of health or disability. ${ }^{10,11}$ The method has two essential ingredients: life tables for males and females based on mortality rates observed in the Australian population; and age- and sexspecific prevalence estimates of health conditions taken from cross-sectional population surveys or other sources. For each sex, the standard life table parameter, $L_{x}$ (the number of person-years lived in the age interval commencing at age $x$ ), was apportioned between the different conditions of health by multiplying $L_{x}$ by the corresponding prevalence measures. Calculation of $T_{x}$ (the total person-years that would be lived after age $x$ ) and $e_{x}^{o}$ (the average years of life remaining for a person who survives to age $x$ ) followed in the usual manner, although separate calculations were made for each condition of health. The final result was the expected years of life spent in each health condition.

Health expectancies were calculated for four mutually exclusive conditions of health:

(i) Not in a health institution and health perceived by the subject as fair to excellent.

(ii) Not in a health institution but health perceived by the subject as poor.

(iii) Occupying a bed in a short-stay hospital.

(iv) Occupying a bed in a long-stay health establishment.

\section{ACTUAL AUSTRALIA}

For actual Australia, the method proceeded as follows. Life tables for Australian males and females were those published by the Australian Bureau of Statistics and based on crosssectional mortality rates in 1990 (table 1). ${ }^{12}$ Self-perceived health status was reported as poor, fair, good, or excellent in the 1989-90 Australian National Health Survey. ${ }^{13}$ As this was a household survey of private and selected non-private dwellings, it did not include persons residing in institutions. Age- and sexspecific prevalence estimates of poor and fair to excellent health status were assumed to apply to the population not occupying a bed in a health institution (table 2).

Age- and sex-specific prevalence estimates of short-stay hospitalisation in Australia were obtained from hospital bed day estimates for 1986 (table 2). ${ }^{7}$ Persons whose usual place of residence was identified in the 1986 Australian Census as a psychiatric hospital or institution, hostel for the disabled, nursing home, or home for the aged were considered to be occupying a bed in a long-stay health establishment. Ageand sex-specific prevalence estimates of longstay institutionalisation were derived from customised census tables from the Australian Bureau of Statistics (table 2). Institutional statistics for 1986 were assumed to be valid for 1990.

Data from the 1989-90 National Health Survey were available only in the age groupings $18-24,25-34,35-44,45-64,65-74$, and $75+$ years. The Survey did not include persons aged less than 18 years. Because of these limitations, the results of analysis were

Table 1 Abridged life tables for adult males and females showing expectations of life for actual Australia in 1990 and estimated for a non-smoking Australia

\begin{tabular}{|c|c|c|c|c|c|c|c|c|}
\hline \multirow{2}{*}{$\begin{array}{c}\text { Age } \\
\text { (years) }\end{array}$} & \multicolumn{4}{|c|}{ Actual Australia 1990} & \multicolumn{4}{|c|}{ Non-smoking Australia } \\
\hline & $l_{x}$ & $L_{x}$ & $T_{x}$ & $e_{x}^{o}$ & $l_{x}$ & $L_{x}$ & $T_{x}$ & $e_{x}^{o}$ \\
\hline \multicolumn{9}{|l|}{ Males } \\
\hline 18 & 98436 & 686050 & 5606582 & 57.0 & 98436 & 686090 & 5915170 & 60.1 \\
\hline 25 & 97543 & 968671 & 4920532 & 50.4 & 97555 & 968950 & 5229080 & 53.6 \\
\hline 35 & 96197 & 954343 & 3951861 & 41.1 & 96253 & 955988 & 4260130 & 44.3 \\
\hline 45 & 94499 & 1788240 & 2997518 & 31.7 & 94829 & 1828125 & 3304142 & 34.8 \\
\hline 65 & 79668 & 692656 & 1209278 & 15.2 & 84521 & 766691 & 1476017 & 17.5 \\
\hline 75 & 56572 & 516622 & 516622 & 9.2 & 66363 & 709326 & 709326 & 10.7 \\
\hline \multicolumn{9}{|l|}{ Females } \\
\hline 18 & 98883 & 691095 & 6214659 & 62.9 & 98883 & 691120 & 6331562 & 64.0 \\
\hline 25 & 98571 & 983412 & 5523564 & 56.1 & 98579 & 983574 & 5640442 & 57.2 \\
\hline 35 & 98080 & 976804 & 4540152 & 46.3 & 98108 & 977437 & 4656868 & 47.5 \\
\hline 45 & 97159 & 1882571 & 3563348 & 36.7 & 97280 & 1894606 & 3679431 & 37.8 \\
\hline 65 & 88655 & 823771 & 1680777 & 19.0 & 90083 & 854277 & 1784825 & 19.8 \\
\hline 75 & 74006 & 857006 & 857006 & 11.6 & 78490 & 930548 & 930548 & 11.9 \\
\hline
\end{tabular}

Key to notations: $l_{x}$ is the number of people alive at age $x ; L_{x}$ is the number of person-years lived in the age interval commencing at age $x ; T_{x}^{x}$ is the total number of person-years that would be lived after age $x ; e_{x}^{o}$ is the average number of years of life remaining for a person who survives to age $x$. 
Table 2 Age-specific prevalence of different conditions of health and institutional care in Australian adult males and females in 1986-90 (smokers and non-smokers combined)

\begin{tabular}{|c|c|c|c|c|}
\hline \multirow[b]{2}{*}{$\begin{array}{l}\text { Age group } \\
\text { (years) }\end{array}$} & \multicolumn{2}{|c|}{$\begin{array}{l}\text { Not in a health } \\
\text { institution }\end{array}$} & \multirow[b]{2}{*}{$\begin{array}{c}\text { Short-stay } \\
\text { hospital })^{\star \star} \\
(\%)\end{array}$} & \multirow[b]{2}{*}{$\begin{array}{c}\text { Long-stay } \\
\text { health } \\
\text { establishment } \uparrow \\
(\%)\end{array}$} \\
\hline & $\begin{array}{c}\text { Fair to } \\
\text { excellent } \\
\text { health } \\
(\%)\end{array}$ & $\begin{array}{c}\text { Poor } \\
\text { health } \\
(\%)\end{array}$ & & \\
\hline \multicolumn{5}{|l|}{ Males } \\
\hline $18-24$ & 98.859 & 0.868 & 0.156 & 0.117 \\
\hline $25-34$ & 98.649 & 1.027 & 0.191 & 0.133 \\
\hline $35-44$ & 97.685 & 1.983 & 0.206 & 0.126 \\
\hline 45-64 & 92.241 & 6.975 & 0.482 & 0.302 \\
\hline $65-74$ & 84.954 & 12.683 & 1.316 & 1.047 \\
\hline $75+$ & 78.025 & 13.307 & 2.595 & 6.073 \\
\hline \multicolumn{5}{|l|}{ Females } \\
\hline & 98.213 & 1.395 & 0.308 & 0.084 \\
\hline $25-34$ & 97.970 & 1.704 & 0.240 & 0.086 \\
\hline $35-44$ & 97.387 & 2.191 & 0.324 & 0.098 \\
\hline $45-64$ & 92.964 & 6.303 & 0.477 & 0.256 \\
\hline $65-74$ & 87.764 & 10.100 & 1.004 & 1.132 \\
\hline $75+$ & 74.101 & 11.476 & 2.379 & 12.044 \\
\hline
\end{tabular}

* Based on the Australian National Health Survey 1989$90 ;^{13}$ self-reported data.

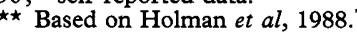

† Based on the 1986 Australian Census.

expressed as expectations of health in adult Australians; ie, as from the 18th birthday. Life table and institutional data were arranged into the corresponding age intervals prior to the calculation of health expectancies.

Years of life expected in each condition of health were obtained by multiplying the $L_{x}$ columns for actual Australia in table 1 by each column in table 2 . The corresponding $T_{x}$ and $e_{18}^{o}$ were then calculated, the latter representing health expectancy at age 18 years.

\section{NON-SMOKING AUSTRALIA}

For non-smoking Australia, the 1990 life tables were adjusted by subtracting the age- and sexspecific mortality rates attributed to tobacco in Australia in 1986, from the total mortality rates. ${ }^{7}$ For each age and sex group, numbers of deaths attributed to tobacco had been obtained in earlier work by applying age-/sex-/diseasespecific aetiologic fractions to the corresponding deaths in Australia in 1986 and summing the age- and sex-specific deaths across all diseases. The aetiologic fractions were obtained from an international meta-analysis of published research on the effects of tobacco on 34 diseases. ${ }^{7}$ The life tables were then reworked in five-year age intervals to obtain revised $l_{x}$, $L_{x}$, and $e_{x}^{o}$ parameters for a theoretical nonsmoking population.

Data on self-perceived poor health status from the 1989-90 National Health Survey were stratified according to smoker status (table 3). Never-smokers in different age-sex categories consistently reported a lower prevalence of poor health status than ever-smokers. The age- and sex-specific prevalences of poor and fair-to-excellent health status in never smokers were taken to apply to the noninstitutionalised population in a non-smoking Australia (table 4). The prevalence of bed occupancy in a short-stay hospital in nonsmoking Australia was calculated for each age-sex group by subtracting, from the nu-
Table 3 Age- and sex-specific prevalence of selfreported poor health status in the 1989-90 Australian National Health Survey according to smoking status

\begin{tabular}{|c|c|c|c|c|c|c|}
\hline \multirow[b]{2}{*}{$\begin{array}{c}\text { Age group } \\
\text { (years) }\end{array}$} & \multicolumn{2}{|c|}{ Ever smoked } & \multicolumn{2}{|c|}{ Never smoked } & \multicolumn{2}{|c|}{ Total } \\
\hline & $\begin{array}{c}\text { Males } \\
(\%)\end{array}$ & $\begin{array}{c}\text { Females } \\
(\%)\end{array}$ & $\begin{array}{c}\text { Males } \\
(\%)\end{array}$ & $\begin{array}{c}\text { Females } \\
(\%)\end{array}$ & $\begin{array}{c}\text { Males } \\
(\%)\end{array}$ & $\begin{array}{c}\text { Females } \\
(\%)\end{array}$ \\
\hline $18-24$ & 1.24 & 1.81 & 0.57 & 1.03 & 0.87 & 1.40 \\
\hline $25-34$ & 1.38 & 1.94 & 0.57 & 1.47 & 1.03 & 1.71 \\
\hline $35-44$ & 2.27 & 2.98 & 1.52 & 1.47 & 1.99 & 2.20 \\
\hline $45-64$ & 8.23 & 6.75 & 4.50 & 6.08 & 7.03 & 6.35 \\
\hline $65-74$ & 14.58 & 13.52 & 8.59 & 8.58 & 12.99 & 10.32 \\
\hline $75+$ & 15.65 & 18.38 & 12.42 & 11.93 & 14.57 & 13.41 \\
\hline All ages $18+$ & 5.68 & 4.88 & 2.55 & 4.46 & 4.46 & 4.64 \\
\hline
\end{tabular}

Table 4 Age-specific prevalence of different conditions of health and institutional care in non-smoking Australian adult males and females in 1986-90

\begin{tabular}{|c|c|c|c|c|}
\hline \multirow[b]{2}{*}{$\begin{array}{l}\text { Age group } \\
\text { (years) }\end{array}$} & \multicolumn{2}{|c|}{$\begin{array}{c}\text { Not in a health } \\
\text { institution }\end{array}$} & \multirow[b]{2}{*}{$\begin{array}{c}\text { Short-stay } \\
\text { hospital } \\
(\%)\end{array}$} & \multirow[b]{2}{*}{$\begin{array}{c}\text { Long-stay } \\
\text { health } \\
\text { establishment } \\
(\%)\end{array}$} \\
\hline & $\begin{array}{c}\text { Fair to } \\
\text { excellent } \\
\text { health } \\
(\%)\end{array}$ & $\begin{array}{c}\text { Poor } \\
\text { health } \\
(\%)\end{array}$ & & \\
\hline \multicolumn{5}{|l|}{ Males } \\
\hline $18-24$ & 99.161 & 0.568 & 0.155 & 0.116 \\
\hline $25-34$ & 99.111 & 0.568 & 0.189 & 0.132 \\
\hline $35-44$ & 98.160 & 1.515 & 0.200 & 0.125 \\
\hline $45-64$ & 94.801 & 4.467 & 0.441 & 0.291 \\
\hline $65-74$ & 89.447 & 8.406 & 1.162 & 0.985 \\
\hline $75+$ & 80.503 & 11.416 & 2.389 & 5.692 \\
\hline \multicolumn{5}{|l|}{ Females } \\
\hline $18-24$ & 98.582 & 1.026 & 0.308 & 0.084 \\
\hline $25-34$ & 98.212 & 1.465 & 0.238 & 0.085 \\
\hline $35-44$ & 97.978 & 1.603 & 0.322 & 0.097 \\
\hline $45-64$ & 93.248 & 6.036 & 0.463 & 0.253 \\
\hline $65-74$ & 89.531 & 8.403 & 0.957 & 1.109 \\
\hline $75+$ & 75.562 & 10.236 & 2.317 & 11.885 \\
\hline
\end{tabular}

* Based on the Australian National Health Survey 1989 90,13 self-reported data.

** Based on Holman ot al, $19888^{7}$

+ Based on the 1986 Australian Census.

merator, the number of bed days attributed to the use of tobacco in 1986. ${ }^{7}$ The method of estimation of tobacco-related bed days was identical to that used to estimate deaths caused by tobacco (see above). ${ }^{7}$ The resultant measures are shown in table 4.

Adjustment of the prevalence of bed occupancy in long-stay health establishments for non-smoking Australia presented special difficulties. Prior to this study there were no estimates available of the aetiologic fractions of bed days in Australian residential care facilities caused by tobacco. Neither was there available an ideal data set on which to base the necessary analysis. We applied two different methods of estimation of residential care aetiologic fractions using such relevant data as were available. Under method A, public-sector nursing home bed days in one Australian state, New South Wales, in fiscal year 1990-1 were tabulated by five-year age group, sex, and principal condition responsible for inpatient stay. The data were provided by the New South Wales Health Department. Disease-specific aetiologic fractions ${ }^{7}$ were then applied to obtain the proportion of nursing home bed days attributable to tobacco in each age-sex group. These proportions were multiplied by the numbers of persons resident in nursing homes, homes for the aged, and hostels for the disabled (but not psychiatric institutions) identified in the 1986 Australian Census. The aetiologic fractions shown in table 5 were derived by dividing the 
Table 5 Age- and sex-specific aetiologic fractions of bed days in Australian long-stay health establishments attributable to tobacco, based on two different methods of estimation

\begin{tabular}{|c|c|c|c|c|}
\hline \multirow[b]{2}{*}{$\begin{array}{c}\text { Age group } \\
\text { (years) }\end{array}$} & \multicolumn{2}{|c|}{$\begin{array}{c}\text { Method } A: \\
\text { NSW Nursing Homes } \\
1990-91\end{array}$} & \multicolumn{2}{|c|}{$\begin{array}{c}\text { Method B: } \\
\text { Australian Disability } \\
\text { Survey } 1988^{8}\end{array}$} \\
\hline & $\underset{(\%)}{\text { Males }}$ & $\begin{array}{c}\text { Females } \\
(\%)\end{array}$ & $\begin{array}{c}\text { Males } \\
(\%)\end{array}$ & $\begin{array}{c}\text { Females } \\
(\%)\end{array}$ \\
\hline $18-24$ & - & - & 0.83 & - \\
\hline $25-34$ & - & 1.80 & 0.66 & 0.39 \\
\hline $35-44$ & 2.77 & 0.08 & 0.49 & 0.77 \\
\hline $45-64$ & 6.35 & 2.53 & 3.72 & 1.24 \\
\hline $65-74$ & 5.06 & 4.21 & 5.88 & 2.02 \\
\hline $75+$ & 8.79 & 2.44 & 6.27 & 1.32 \\
\hline
\end{tabular}

resultant numerators by the total numbers of people resident in long-stay health establishments (including psychiatric institutions).

Under method B, customised data from the 1988 Australian Survey of Disability and Handicap were obtained from the Australian Bureau of Statistics. ${ }^{8}$ The data were restricted to disabled persons resident in health establishments and were tabulated by age, sex, and type of primary disabling condition identified by the respondent or a proxy responding on his or her behalf. Disease-specific aetiologic fractions were applied, and the numbers of persons with disabilities caused by tobacco were divided by the total disabled population in health establishments to derive the age- and sex-specific aetiologic fractions shown in table 5. The aetiologic fractions obtained by method B tended to be conservative relative to those obtained from method A (table 5), and therefore, method $B$ was carried over into the results presented in the last column of table 4 . The prevalence of bed occupancy in a longstay health establishment in non-smoking Australia was estimated by adjusting the ageand sex-specific measures shown in table 2 , using the aetiologic fractions under method $B$ in table 5 .

To obtain years of life expected in each condition of health, the $L_{x}$ columns for nonsmoking Australia in table 1 were multiplied by each column in table 4 . The corresponding $T_{x}$ and $e_{18}^{0}$ followed in the usual manner.

\section{Results}

From table 1 it may be seen that expectations of life at age 18 years were increased by 3.12 years in males and 1.19 years in females in non-smoking Australia compared with actual
Australia. Because only $27-30 \%$ of adults in actual Australia are current smokers, these differences in life expectancy were less than the average reduction in life expectancy for cigarette smokers compared with non-smokers, reported as five to eight years by the US Surgeon General. ${ }^{14}$

Health expectations for adult males and females at age 18 years are shown in table 6 for actual Australia and non-smoking Australia. For adult males, length of life in fair to excellent health increased by 3.67 years. This result was 0.55 years greater than the increase in total life expectancy. Years of life spent in the community in poor health were reduced by 0.66 years (eight months), whereas there were small increases in the average time spent in health institutions. Expected duration in shortstay hospitals increased by 0.02 years (one week) and the average duration in long-stay health establishments increased by 0.09 years (about one month).

The differences between actual Australia and non-smoking Australia were smaller for adult females. The expectation of fair to excellent health increased by 1.40 years and time spent in poor health while resident in the community fell by 0.30 years (almost four months). Duration of short-stay hospitalisation increased in females in non-smoking Australia by 0.01 year (less than one week) and long-stay residential care increased by an average of 0.08 years (about the same as in males).

Results produced using method A to estimate the aetiologic fractions of bed days in long-stay health establishments were little different from those reported in table 6 . For non-smoking Australia, the expected duration of residential care was 0.56 years in adult males (instead of 0.57 years) and 1.27 years in adult females (instead of 1.29 years).

\section{Discussion}

Warner has reported in the United States (US) that the attainment of a tobacco-free society would extend average life expectancy by one to two years for the population as a whole and by approximately 15 years for the average person who would have died from a condition caused by tobacco. ${ }^{15}$ Although he did not perform a health expectancy analysis, Warner surmised that the fall of tobacco consumption would exacerbate the current trend towards an older America, and that the predominant health care

Table 6 Health expectations for adult males and females at age 18 years for actual Australia in 1990 and estimated for a non-smoking Australia. Values are years

\begin{tabular}{|c|c|c|c|c|c|}
\hline & \multirow[b]{2}{*}{$\begin{array}{l}\text { Total remaining } \\
\text { years of life }\end{array}$} & \multicolumn{2}{|c|}{ Not in a health institution } & \multirow[b]{2}{*}{$\begin{array}{l}\text { Short-stay } \\
\text { hospital }\end{array}$} & \multirow[b]{2}{*}{$\begin{array}{l}\text { Long-stay } \\
\text { health } \\
\text { establishment }\end{array}$} \\
\hline & & $\begin{array}{l}\text { Fair to } \\
\text { excellent } \\
\text { health }\end{array}$ & Poor health & & \\
\hline \multicolumn{6}{|l|}{ Males } \\
\hline $\begin{array}{l}\text { Actual Australia } \\
\text { Non-smoking Australia }\end{array}$ & $\begin{array}{l}56.96 \\
60.08\end{array}$ & $\begin{array}{l}52.90 \\
56.57\end{array}$ & $\begin{array}{l}3.21 \\
2.55\end{array}$ & $\begin{array}{l}0.37 \\
0.39\end{array}$ & $\begin{array}{l}0.48 \\
0.57\end{array}$ \\
\hline \multicolumn{6}{|l|}{ Females } \\
\hline $\begin{array}{l}\text { Actual Australia } \\
\text { Non-smoking Australia }\end{array}$ & $\begin{array}{l}62.85 \\
64.04\end{array}$ & $\begin{array}{l}57.66 \\
59.06\end{array}$ & $\begin{array}{l}3.52 \\
3.22\end{array}$ & $\begin{array}{l}0.46 \\
0.47\end{array}$ & $\begin{array}{l}1.21 \\
1.29\end{array}$ \\
\hline
\end{tabular}

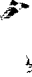


industry implications would consist of an altered mix of morbid conditions and shifts in the need for particular types of medical specialities and health care facilities. He predicted that needs for oncologists, pulmonary physicians, and neonatologists would be reduced, whereas the need would increase for gerontological services. ${ }^{15}$

The immediate conclusion one draws from the present analysis is that elimination of exposure to tobacco smoke is likely to increase the life expectancy of the average Australian, by an extra three years in males and just over one year in females, without an undesirable effect on the overall prevalence of ill-health. With the health expectations in table 6, a steadystate population of adult male non-smokers would eventually move towards a prevalence of perceived poor health or bed occupancy in a health institution of around $5.8 \%$. This compares with $7.1 \%$ in actual Australia. For adult females the corresponding proportions would be $7.8 \%$ and $8.3 \%$. However, it is predicted that ageing of a smoke-free population would result in a slight shift towards greater institutional care of those with health problems. It is predicted that in adult males the prevalence of bed occupancy in a health institution would increase from $1.5 \%$ to $1.6 \%$, and for adult females from $2.7 \%$ to $2.8 \%$. Most of this small increase would occur in bed occupancy in long-stay health establishments rather than in acute hospitals.

Taken at face value these results may be considered from the perspectives of the public health advocate and the health service administrator. For the public health advocate the case in support of tobacco control is convincing. For example, an average male in nonsmoking Australia gains three additional years of life free of serious illness and reduces his overall duration of poor health by about six months. These benefits are delivered at the cost of an additional one week in hospital and an additional one month in residential care. In adult women the benefits and costs are somewhat similar, but proportionately reduced.

For a health service administrator who is concerned solely about health care costs, and not about the advancement of health per se, the predicted final outcome of tobacco control in Australia may bring a mixed result. Ageing of the population may cause a slight increase in institutional costs, but these would be offset by a reduced demand for ambulatory health care due to the reductions in the time people would spend in the community in a perceived state of poor health.

The interpretation of these results and immediate conclusions must be tempered by acknowledgement of the possible sources of error. All of the figures presented are estimates and are subject to random error. Although calculation of standard errors was beyond the scope of this study, other work has shown that the relative standard errors of health expectancies in actual Australia are of the order of $0.5 \%{ }^{16}$

Of more concern are several potential sources of systematic error. While it is bio- logically plausible that a higher proportion of smokers would perceive their health to be poor, at least some confounding of this relationship by extraneous factors cannot be excluded. It is possible that persons in a position of relative social disadvantage, who are known to have a higher prevalence of smoking, considered their health poor for reasons related to their social circumstances. It is also possible that the results were confounded by extraneous biomedical determinants of health status. Special tabulations of data obtained from the Australian National Health Survey showed that the prevalence of "high-risk" alcohol consumption was $5.8 \%$ in ever-smokers compared with $1.5 \%$ in neversmokers. However, the interpretation of this finding must take into account the higher proportion of teetotallers among neversmokers $(39.8 \%)$ as against ever-smokers $(26.2 \%)$, and evidence that abstinence from alcohol may increase the risk of morbidity and mortality from cardiovascular disease. ${ }^{7,17}$ Little or no difference in the National Health Survey was observed between smokers and other respondents in dietary behaviours, including removal of excess fat from meat $(7.6 \%$ in eversmokers and $7.7 \%$ in never-smokers), avoidance of fried foods $(3.7 \%$ and $3.6 \%$ ), no added salt in the diet $(5.7 \%$ and $6.0 \%)$, and no added sugar (both $6.2 \%$ ).

Each of the two methods of estimating aetiologic fractions of bed days in long-stay health establishments caused by tobacco had its strengths and weaknesses. Method A had the advantage of higher quality diagnostic information, supplied by medical officers attending the nursing homes, but had the disadvantage of exclusion of nursing homes in the private sector, which provide $58 \%$ of nursing home beds in Australia. ${ }^{18}$ Tobaccocaused conditions may be over-represented in public-sector nursing homes due to socioeconomic effects. Method B used data sampled from all health establishments in Australia, but suffered from the weakness that the diagnostic information was mainly self-reported. Some diagnostic labels were vague and difficult to interpret. For example, $5 \%$ of disabled persons in health establishments suffered from "paralysis". According to the rules of the International Classification of Diseases this is to be coded under diseases of the nervous system rather than under cerebrovascular disease. Therefore, we did not apply the aetiologic fractions for cerebrovascular disease to "paralysis", despite our suspicion that many of these persons were paralysed due to stroke. Our opinion is that method A tended to overestimate whereas method B tended to underestimate the true situation. However, as reported above, the final results were not materially different, whichever method was used.

The analysis suffers from the drawback that cross-sectional mortality rates and prevalence data are used to draw conclusions about the lifetime experiences of future generations of Australians. Cohorts born today are likely to experience a lower force of mortality through- 
out life than present cross-sectional rates would suggest. They may be subject also to different rates of morbidity and admission to institutional care compared with those prevailing in 1990, due to advances in medical technology and changes in health care policy. It is reasonable to speculate that most of these factors would tend to reduce the duration of institutional care in the elderly, and from this stand-point the analysis presented here may be regarded as depicting a worst-case scenario.

Finally, it should be acknowledged that the results for Australian women compare existing statistics with those estimated for a future smoke-free society in which all adverse effects of tobacco have passed. The reality is that because the epidemic of tobacco-caused disease is still increasing in Australian women, ${ }^{5}$ their situation is likely to deteriorate further before it improves.

Despite the data limitations, health expectancy analysis provides a useful technique for estimating the long-term implications of tobacco control for the population's health. The tobacco-control movement is based on humanitarian motives rather than financial profits. As such, it is able to distinguish itself from the tobacco industry by its determination to ensure that tobacco control policies are subjected to constant scientific scrutiny. An important issue concerning the population ageing effects of tobacco control has been addressed in this paper. In as much as the results represent the best available estimates of the effects of tobacco control on health expectancy, a significant net health benefit is predicted for the average Australian. It would be reasonable to generalise this conclusion to the populations of other developed countries, having similar profiles of mortality, chronic disability, and tobacco consumption.
The Health Promotion Development and Evaluation Programme is an independent academic programme supported by the Western Australian Health Promotion Foundation.

1 Winstanley $\mathrm{MH}$, Woodward SD. Tobacco in Australia - an

2 Winstanley $\mathrm{MH}$, Woodward SD. Tobacco in Australia : facts and issues. Volume 2. Sydney: ASH (Action on Smoking and Health) Australia, 1993 (in press).

3 Australian Bureau of Statistics. Customs and excise revenue, Australia. Canberra : Commonwealth Government Printer, 1991. (ABS Catalogue No 5427.0)

4 Hill DJ, White VM, Gray NJ. Australian patterns of tobacco smoking in 1989. Med $\mathcal{f}$ Aust, 1992; 154: 797-801.

5 Holman CDJ. Lung cancer - The down side of the epidemic curve. Cancer Forum 1991; 15: 169-70.

6 Giles GG, Hill DJ, Silver B. The lung cancer epidemic in Australia, 1910 and 1989. Aust $\mathcal{F}$ Public Health 1991; 15: $245-7$.

7 Holman CDJ, Armstrong BK, et al. The quantification of drug-caused morbidity and mortality in Australia 1988. Part 2. Canberra: Department of Community Services Part 2. Canberra:

8 Australian Bureau of Statistics. Disability and handicap Australia, 1988. Canberra: Commonwealth Government Printer, 1990. (ABS Catalogue No 4120.0)

9 Sullivan DF. A single index of mortality and morbidity. HSMHA Health Reports 1971 ; 86: 347-54.

10 Wilkins R. Health expectancy in Canada, late 1970s: demographic, regional, and social dimensions. Am $\dot{f}$ Public Health 1983; 73: 1073-80.

11 Graham P, Davis P. Life expectancy free of disability: A composite measure of population health status. Community Health Stud 1990; 14: 138-45.

12 Australian Bureau of Statistics. Deaths Australia 1990 Canberra: Commonwealth Government Printer, 1990 (ABS Catalogue No 4120.0)

13 Australian Bureau of Statistics. 1989-90 National Health Survey users' guide. Canberra: Commonwealth Government Printer, 1991. (ABS Catalogue No 4363.0)

14 US Department of Health, Education, and Welfare. Smoking and health: a report of the Surgeon General. Washington, DC: DHEW, 1979. (DHEW Publication No (PHS) 79-50066)

15 Warner KE. Health and economic implications of a tobaccofree society. $\mathcal{F} A M A 1987 ; 258$ : 2080-6.

16 Mathers C. Health expectancies in Australia 1981 and 1988. Canberra: Australian Government Publishing Service, Canber.
1991.

17 Holman CDJ, Armstrong BK. The quantification of alcohol-caused morbidity and mortality in Australia: the alcohol-caused morbidity and mortality in Austra
authors respond. Med $\mathcal{f}$ Aust 1992; 157:560-1.

18 Grant C, Lapsley HM. The Australian health care system 1991. Sydney: University of New South Wales, 1992. (Australian Studies in Health Service Administration No. 74.) 